\title{
Layers of Consciousness: An Autoethnographic Study of the Comprehensive Exam Process
}

\author{
Allyson Kelley \\ University of North Carolina Greensboro, \\ Greensboro, NC, USA
}

A kelle2@uncg.edu

\begin{abstract}
Comprehensive exams mark a turning point in the careers of doctoral students; however, most doctoral programs do not fully prepare students for the comprehensive exam process. This paper provides an overview of autoethnography as a valid qualitative research method to explore one doctoral student's journey through the exam process. A reflexive narrative approach informed by feminist and constructivist perspectives describes and gives meaning to the process. The author describes and interprets her experience, emotions, and encounters with self and with others during the exams. It is through this process the author finds meaning, history, and reflections for the future. This paper concludes with recommendations, thoughts about how doctoral committees can best support students, and the need for additional flexibility and supports for doctoral students with family responsibilities.
\end{abstract}

Keywords: Autoethnography, comprehensive exams, doctoral studies, graduate student, qualitative methods.

\section{Introduction}

Autoethnography is a qualitative research method based on writing and reflection that allows researchers to explore personal experiences through social, cultural or political contexts. It works best when the researcher seeks to gain a cultural understanding of self and others (Chang, 2008). In this approach, the researcher is both the subject and the researcher. Autoethnographic research methods help answer research questions relating to an experience that is not well understood or lived by others. In the past, autoethnography was mainly used by disciplines such as anthropology, sociology, and education; yet today autoethnographic research approaches are emerging as a valid and meaningful research method by other disciplines including psychology, health sciences, and political science (Creswell, 2007; McIlveen, 2008). However, researchers from more positivist and empirical orientations feel autoethnographic approaches are not valid and therefore not an appropriate method for research within the academic institutions. Thus, the purpose of this paper

Material published as part of this publication, either on-line or in print, is copyrighted by the Informing Science Institute. Permission to make digital or paper copy of part or all of these works for personal or classroom use is granted without fee provided that the copies are not made or distributed for profit or commercial advantage AND that copies 1) bear this notice in full and 2) give the full citation on the first page. It is permissible to abstract these works so long as credit is given. To copy in all other cases or to republish or to post on a server or to redistribute to lists requires specific permission and payment of a fee. Contact Publisher@InformingScience.org to request redistribution permission. is to demonstrate the use of autoethnography as a valid research method within the academy. The author uses feminist and constructivist perspectives to situate the meaning of the experience within a broader body of literature and through this, discovers the meaning of the doctoral comprehensive exam process.

This paper provides an overview of autoethnography as a valid qualitative re- 
search method and takes the reader through a step-by-step process of the autoethnographic process. A reflexive narrative approach is used to construct and describe the doctoral comprehensive exam process. This creates a story. The author describes and interprets her experience, emotions, and encounters with self and with others during the exams. It is through this process the author finds meaning, history, and reflections for the future. This paper concludes with recommendations, both how doctoral committees can best support students, and the need for additional flexibility and supports for doctoral students with family responsibilities.

\section{Forms of Autoethnographies}

Autoethnography is based in theory and practice through various forms of critical inquiry (McIlveen, 2008). Multiple forms of autoethnography exist, for example, analytic, community, personal narratives, co-constructed narratives, and evocative (Ellis, Adams, \& Bochner, 2011). Like other qualitative research methods (Carter \& Little, 2007), autoethnographic forms serve different purposes. For example, the analytic form of autoethnography often seeks to establish objectivity whereas the evocative form aims to generate empathy from the reader (McIlveen, 2008). In comparison, community autoethnographies use the experiences of researchers working in partnership with a community to describe social and cultural context (Vande Berg \& Trujillo, 2008). Of all autoethnographic forms, personal narratives are the most controversial. Some feel that researchers who write about themselves (personal narratives) are arrogant, self-absorbed, full of emotion, and lacking understanding about what constitutes research. However, others feel that personal narratives serve an important purpose because they allow researchers to be both authentic and vulnerable while connecting with others to share their reflection and experiences (Ellis, 1999).

Table 1: Autoethnography, Ethnography, Biography, and Autobiography

\begin{tabular}{|l|l|l|l|l|}
\hline \multicolumn{1}{|c|}{ Type } & $\begin{array}{l}\text { Autoethnogra } \\
\text { phy }\end{array}$ & Ethnography & \multicolumn{1}{|c|}{ Biography } & Autobiography \\
\hline $\begin{array}{l}\text { Who and } \\
\text { What? }\end{array}$ & $\begin{array}{l}\text { Self, culture, } \\
\text { personal ex- } \\
\text { periences }\end{array}$ & $\begin{array}{l}\text { Others, cul- } \\
\text { ture }\end{array}$ & Others, Story & Self, Story \\
\hline Why? & $\begin{array}{l}\text { Meaning, } \\
\text { empathy }\end{array}$ & $\begin{array}{l}\text { Understandin } \\
\text { g }\end{array}$ & Historical events & Interest \\
\hline $\begin{array}{l}\text { Research } \\
\text { Method? }\end{array}$ & Yes & Yes & No & No \\
\hline $\begin{array}{l}\text { Theory } \\
\text { Driven? }\end{array}$ & Yes & Sometimes & No & No \\
\hline $\begin{array}{l}\text { When to } \\
\text { Use? }\end{array}$ & $\begin{array}{l}\text { Understandin } \\
\text { g experience } \\
\text { of self and } \\
\text { culture, eth- } \\
\text { ics, politics }\end{array}$ & $\begin{array}{l}\text { Understandin } \\
\text { g other cul- } \\
\text { tures }\end{array}$ & $\begin{array}{l}\text { Individual's story im- } \\
\text { portant for history }\end{array}$ & $\begin{array}{l}\text { Self, story that must } \\
\text { be told }\end{array}$ \\
\hline
\end{tabular}

Similarities and differences between autoethnography, ethnography, biography, and autobiography must be recognized to fully realize the potential of autoethnography as a research method. Unlike ethnographic research, where researchers use observations and interviews to gain understanding of others, autoethnographic research uses the researcher's own experiences to gain understanding and make meaning of experiences (Polkinghorne, 1991). There are differences between each approach that can be answered by these questions: 'Who is the subject of research?' 
'What is the subject of research?', 'Why or for what purpose?' Table 1 describes differences between approaches, yet all forms seek to further understanding of self, others, culture, history, or interest.

\section{Value of autoethnography}

Ellis (2000) describes autoethnography as art, science, and self. As a research method, autoethnography requires reflexivity, subjectivity, vulnerability, and authenticity.

Autoethnographies work best when they are applied to an experience or context from which the author seeks to understand or derive meaning. Often these experiences involve conflict and are situated within a broader social context or worldview.

Several examples of autoethnography exist in published literature, across multiple disciplines. For example, Langhout (2006) used autoethnography to further understanding of community psychology and demonstrate research collaboration. Mcllvven (2008) used autoethnography in vocational psychology for establishing career counseling procedures. Others have used autoethnography to generate new understanding about training experiences of counselors (Meekums, 2008), further educational research (Starr, 2010), and expand understanding of professional leadership and management (Kempster \& Stewart, 2010).

\section{Criticisms of autoethnography}

Critics of ethnographic approaches feel they are not research, but just stories (Ellis, 1999). Many qualitative and ethnographic researchers have countered this argument by demonstrating stories that emerge from ethnographic approaches that deepen our understanding of the world (Ellis, 2004; Reissman, 2008). Unlike more traditional forms of scientific research, objectivity is not the intention or goal and results are not generalizable to other populations, cultures, individuals, or experiences. Some feel autoethnographies lack rigor, theory and analytical components (Ellis, 1999). Others feel it is not possible to write publically and ethically (Delamont, 2007). The irony is that critics feel that autoethnographies focus too much on people who already have power and privilege (Becker, 1967), yet most autoethnographers disagree. They feel the primary purpose of their research and writing is to achieve social justice (Ellis et al., 2011) and to give away their privilege and power by deepening understanding of the actual social, cultural, and political structures in place that oppress those without power and privilege.

\section{Validity and Reliability}

Unlike other approaches to research, autoethnographers achieve validity and reliability by establishing a connection with the reader. Within autoethnographic approaches, truth is what makes writers want to write and readers want to read. There is a vulnerability that comes from emotions, feelings, and memories that forms the basis of an emergent truth we seek to replicate through story rather than an absolute truth that more traditional research approaches seek to achieve. Emergent truth relates to validity and requires the writer to tell his or her story in such a way that the reader sees, feels, and experiences the events from the writer's perspective. Ellis and colleagues (2008) write that validity is achieved when the reader feels empathy toward the writer and subject matter.

Reliability is related to validity, but seeks to establish the credibility of writer. The reliability of autoethnography might be assessed by the likelihood that the author actually experienced the events he or she writes about in the way narratives are written (Ellis et al., 2011). Along these lines, it is worth mentioning that while autoethnographies are not meant to be generalizable, they must resonate with readers in a way that helps them understand an unfamiliar experience (Ellis, 2004). Finally, in qualitative research, there is an inherent subjectivity and bias that must be 
acknowledged by the reader, subject, researcher, and critics. Autoethnography is perhaps the most biased, influenced, and interpretive form of qualitative research. Researchers must disclose this bias to the reader with the goal of helping the reader derive meaning from experiences shared and the worldview from which the author writes.

\section{Selection of Reflective Narrative Autoethnographic Approach}

A reflexive narrative autoethnographic approach (Berry, 2006; Ellis, 2004; Reissman; 2008) was selected because it allowed the author to examine the layers of journal entries written during the exam process. Ellis is one of the main writers and experts on autoethnography as a research method; she writes that autoethnography is "part auto or self and part ethno or culture" (p. 32). She goes on to define autoethnographies as "writing about the personal and its relationship to culture.... that displays multiple layers of consciousness (p. 37, 2004). Several other authors have written about what autoethnography is and what it is not, including Denzin (1994), Ellis et al. (2008), Spry (2001), and Wall (2008). There are subtle differences in how the authors describe an autoethnographic approach, yet most agree that autoethnography is a form of narrative inquiry (Chang, 2008). Autoethnography also compliments the goals of social science research in a postmodern environment (Wall, 2008) where there is not just one truth, but many emergent truths.

The sections that follow use an autoethnographic approach informed by theoretical and practical insights (Jones \& Alony, 2011) to illustrate how autoethnographic approaches can be employed by doctoral students and researchers from a variety of disciplines as a valid method. This requires a mix of first and third person text where the first person text is in italics and represents the author's subjective experiences and the third person text represents theoretical and methodological insights from the field. This story is what I carry with me as a researcher, and in this case the subject of research. I am the author, the researcher, and the subject. In this paper, I will tell you about my experience in the doctoral comprehensive exam process. This telling is important because it is how I disclose my biases that influence my understanding, experience, and interpretation of events that led up to and culminated in the completion of doctoral comprehensive exams.

\section{The Researcher and the Researched}

An autoethnographic approach was selected by the author to explore and make meaning of the comprehensive exam experience (Polkinghorne, 1991), and through this process the author came to understand her own life, self, history, and connection to the world. I am a 37-year old female. I am a mother, wife, gardener, traveler, auntie, sister, mentor, student, and friend. I have spent most of my life in the Western United States although at the present time I live in North Carolina. I value honesty, family, hard work, loyalty, humility, spirituality, and community.

Looking back in time, at my first experience with the college, I was just 17. I enrolled in a community college immediately following high school and failed. I was not interested in college, I wanted to experience the world and that is what I did. Ten years passed and I was tired of barely getting by financially and working dead-end jobs. I decided to try college again. I was successful, earned my bachelor's degree and went on to get a graduate degree. I taught at a small private college, worked as a community based researcher, and evaluated community-based programs. During this time I worked with various people within the academy, most of whom had a ' $D$ ' behind their names (PhD, MD, DrPH, and ScD). I wanted the 'D' because I did not have one, and everyone who had a 'D' acted like they knew more than me. I applied to a doctoral program (DrPH) and was accepted. After I finished my course work, I endured the comprehensive exam process. This paper is about my story (narrative), context, and meaning (significance) of comprehensive exams. 


\section{Data}

Data collection and analysis in autoethnographic research is similar to other forms of qualitative research. Data were collected by the author, analyzed, and the interpretation was then written. Data included participation in certain events, observations of self and self in relation to others, writing and reading daily journal entries, various emails sent during the exam process, and conversations the author had with herself and with others. Data were verified by triangulating several data sources and experiences. Data were then analyzed and interpreted to determine the meaning of the experience in relation to the comprehensive exam process. Feminist and constructivist perspectives were used by the author when reviewing the data because the author was most interested in understanding the experience and how it related to gender and her family responsibilities. Following the recommendations of Chang (2008), the author was careful and critical of the data because the overall purpose of the experience was to find meaning based on what was recalled, observed, or felt during the experience. This gave the author a deeper understanding of her often conflicting roles as a mother and doctoral student. First the author wrote autobiographical texts about her experience in the exam process and journals, letters, and memos during the 3 -week exam process. She also reflected on the oral exam process, what she did, what was said, and how she felt. After the process was complete, she used the autobiographical texts to create an autoethnography.

\section{Theory}

Theory helped the author relate the significance of the comprehensive exams within a broader cultural, political, and social context. I read Guba and Lincoln's (1994) work on paradigm positions and practical issues (p.112) that inform qualitative research. This prompted me to select feminist and constructivist perspectives to relate my experience to an existing body of literature and thought.

The feminist perspective allowed the author to describe her experiences as a woman and was based on the idea that women and men interpret and experience the world around them differently (Smith, 1987). The constructivist paradigm asserts that the nature of knowledge is based on individual reconstructions and consensus and is hermeneutic, dialectal and is useful for reconstructing previously held beliefs, thoughts, or ways of knowing (Guba \& Lincoln., 1994, p. 111). This paradigm seeks to increase understanding of the world and helped the author reconstruct the history, days, and events that made up the comprehensive exam process.

The exam was not simply three weeks of my life; it was 37 years of believing, thinking, and knowing. Both feminist and constructivist perspectives required me to examine my own beliefs about what a doctoral degree means, my role as a mother and wife, the treatment of women within the academy, and the need for additional support.

Now that I have increased your understanding about autoethnographic approaches, theory, and data, I will tell my story. The purpose of this story is to increase understanding of the comprehensive exam process, shed light on the selection of research methods from a doctoral student's perspective, and demonstrate the application of an autoethnographic research as a method. I use relevant literature, journal entries and excerpts from letters I wrote to committee members during the comprehensive exam process - this provides an emic perspective, meaning an insider's (me) thoughts, feelings, and experiences of the exam process and culture of academe. In contrast, etic perspectives focus on generalizations and limits ethnocentric, cultural or political bias. I begin with an overview of the comprehensive exam process and how it relates to me and to the broader social, political and cultural norms within the academy that make it difficult for women to achieve doctoral status and maintain high faculty ranks within the academy. 


\section{Overview of Comprehensive Exams}

Comprehensive exams mark a turning point in the careers of doctoral students. However, most doctoral programs do not fully prepare students for the exam process (Ali \& Kohun, 2007). Often exam questions require students to draw on their own experiences, professional positions, and test newly acquired doctoral skills. The exam process varies by discipline, university, department, degree, and committee, but the outcome is the same, students either pass or fail. An estimated $50 \%$ of doctoral students who enter doctoral degree programs drop out before they graduate (Smallwood, 2004); but less is known about the experiences of doctoral students and the rigorous comprehensive exam process. Students who pass the comprehensive exam process often go on to write and defend dissertation proposals, advance to candidacy, and then graduate with doctoral degrees.

Students with newly acquired doctoral degrees represent the new face of academia, where women and minorities are gaining ground and diversifying the traditionally white male-dominated faculty ranks (Aguirre, 2000). Yet, recent studies report that gender inequality persists within academy despite the fact that women are now earning doctoral degrees at about the same rate as men (Winslow, 2010). Gender inequalities are evident in the ways that women faculty members achieve promotion and tenure to full professor at a slower rate than their male counterparts; women are less likely to hold administrative positions, and they earn less than men (Krefting, 2003; Winslow, 2010). Therefore, it is critical to understand possible reasons for gender inequalities and how to best support the continued diversification of women and minorities within the academy through the doctoral granting process.

One possible reason for gender inequalities might be related to family status. Previous studies report that parenthood impacts women's employment experiences more than men's (Kaufman \& Uhlenberg, 2000), and often implicit and explicit biases exist toward faculty members with family dependents and responsibilities. For example, within the academy, the ideal faculty member is an individual with a partner at home to manage the day-to-day needs of dependents and family life (Winslow, 2010). Institutions must recognize that to best support doctoral students with family dependents and responsibilities, changing norms, promoting flexibility for work-life balance, and additional understanding are often required. This recognition is not only needed once students earn their doctoral degrees and begin working in the new academy, but also during the doctoral preparation process, including coursework, comprehensive exams, and dissertation research.

In the overview of comprehensive exams above, I provide context, rationale, and meaning to capture the reader's attention. As a general rule, the validity of autoethnography is based on the premise that the author tells a story and situates the context with relevant literature and paradigmatic approaches. At this point in the autoethnography process it would be difficult to establish validity of the method if I, the author (and subject), had never experienced academia or the comprehensive exam process. This is the distinguishing aspect of autoethnography as a method; it requires the researcher and subject to share an experience with transparency and vulnerability.

\section{Student, Committee, and Context}

The doctoral committee included five members: 1 anthropologist, 2 epidemiologists, 1 Dean of Research, and 1 public health researcher. Three are males and two are female. The autoethnography that follows was written one month after I submitted my final written comprehensive exams and 4-days after the oral exam process. The excerpts below are the data I used to describe the comprehensive exam experience. These data come from exam questions sent via email, daily journal entries, letters to committee members that accompanied exam answers, and my emotions and reflections during the experience. I used a reflexive approach to examine and make meaning of the experience as it relates to the broader social, cultural, and political context that I, as the 
researcher and subject live. This story (autoethnographic data) begins with an email and my first journal entry on the third day of written comprehensive exams.

\section{Exam Question 1}

Exam Question 1 arrived via email at 8:17am Monday morning. The author had 13 days to respond (Table 2).

\section{Table 2. Comprehensive Exam Question 1}

You have two weeks to complete this first comprehensive exam section. Please submit your written responses to all committee members by the close of business on May 17.

What are some currently unanswered questions related to the high rates of diabetes affecting American Indian/Alaska Native populations? Pick one of these unanswered questions and design a mixed-methods study that you think would help to answer that question.

\section{Days into Comprehensive Exams}

It is 6am, I have been up for 3 hours, and well longer if you count being up throughout the night to care for a sick child, but the point is that I am not functioning well due to inadequate sleep. As a mother, the role of caring for our children always supersedes school work.

3 days into a 14 day comprehensive exam process and absolutely piles of papers but no direction on where I want to go. I feel overwhelmed with the task of designing an intervention study that will actually work, and not simply duplicate what millions of others have done (that has failed to work). The challenge is presenting something new, with the risk of it being a flop, or not well received by the committee because it is so drastically different than what others have proposed in previous interventions.

\section{Day 4 Finding Direction}

After reading most of yesterday, in-between caring for a sick child I have come to a place where I am feeling comfortable about the direction of what my responses will be. I am excited to begin writing and have about 60 sticky notes all over my computer with relevant literature. I wish I would have read up on this area before I got the questions because it feels completely new, almost discovery and my mind has never conceived these things before.

\section{Day 5}

Woke up at 4am then slept until 5:30am, got up and dove into the literature. I am still finding a ton of articles that I need to read, but time is running out. I need to just go for it. Went to yoga, this helped clear my mind. I was driving and somewhat overcome with emotion, feelings of complete inadequacy, overwhelming joy that I am to this point, and feelings of support from all of the people that have mattered to me. I feel like the voices of the authors in the manuscripts are really coming alive now. I can almost see them, and what they mean. This is helping me get a handle on what my proposed research exam question will be.

\section{Day 6: Cleaning done}

I am getting a lot of cleaning done; I even pulled my antique sheets and table cloths out, bleached and pressed them. Good thinking time. Oh, and I finished a fidelity manuscript and sent to other authors for comment. Why am I doing this? I hope today is productive - day 6 no shower, still in pajamas, child is better.

\section{Day 8}

I have had the questions for a week and I am finally finding my groove. The literature is starting to say the same thing, or at least I am not discovering new publications every time I look or read 
an article. I think this is a good sign. Yesterday I had the bright idea of spending 3 hours looking for funding opportunities that might fund the proposal. More time wasted.

What I have come to realize is that theories are difficult to apply and use in community contexts. Daniels and Green said this in their 1999 publication about a community-based intervention that failed. I have not read anything since this article that made it so clear, and most authors would not write this, and many would not publish it.

The good news is I have the first question answered based on the mass amount of knowledge I have collected over the last 7 days..... I am beginning to find my groove.

\section{Day 13: Blank}

I have one day to bring this all together. The house is a mess, papers are everywhere, it is 3 am and I have been up for an hour drinking coffee contemplating my future. I wanted to write the last several days but could not find the time to do so. The most surprising thing that has happened during this process is the emotion. I think the emotion comes from feeling overwhelmed that all of this thinking is going to come to an end soon. I also feel inadequate like whatever I write will not be good enough. It is kind of like the last step in faking everyone out. Imposter syndrome is at an all-time high. With 1 day left I am trying to organize everything (maybe 60 documents of misspelled, incomplete paragraphs) and write the proposal I will submit.

I cannot wait for this to be over. I feel guilty that I have not spent any time with my daughter, I missed her first swim lesson and she always talks about me working instead of playing with her. This will be over soon.

\section{Reflection on Exam Question 1 Submitted}

I spent 12-days on exam question 1 . On the $12^{\text {th }}$ day, I woke up at 230am with a blank document. I realized I was out of time so I filled the empty document with words that would eventually be a mixed method study that would answer exam question 1. I submitted my responses but did not receive any confirmation from my committee and this increased my anxiety. However, I had the weekend to spend with my family and take care of household responsibilities before getting the second set of exam questions.

At this point in the process, the author has demonstrated vulnerability, truth and a struggle between the worlds of at home responsibilities and a soon to be academic. Situating the comprehensive exam process within a feminist paradigm allowed the author to describe her experiences as a woman and mother with truth and vulnerability that is not often voiced in more traditional research methods. Validity and reliability is established through a connection with the reader and an emergent truth found through story.

\section{Exam Question 2}

Exam Question 2 arrived via email at 8:37am Monday morning and the author had 5 days to respond (Table 3).

\section{Day 17}

I turned in Exam Question 1 on Friday at 5:30. My printer broke, no time to proof and feels a bit clunky but I did what I could and looking back I feel pretty good about the process- maybe not the outcome but what I learned. I hope my committee feels the same way-major holes in the theoretical approach since there does not seem to be one that actually works, and the struggle with how to write something that would be realistic and not just placate academics or satisfy the requirement felt insurmountable at times.

This morning I received Exam Question 2 and I feel much better about my plan. I am going to write like crazy in the next two days and aim to submit the draft by Thursday afternoon. I simply cannot wait until the day before to start writing like I did last time. Here I go. 


\section{Table 3. Comprehensive Exam Question 2}

You have one business week to complete this exam section. Please submit your written response to all committee members by the close of business on May 24. Prepare an essay of no more than 10 pages, single-spaced that discusses the dilemmas you face as a white researcher conducting research on issues facing Native American populations in the communities in which you work. You should include historical and personal examples (from the literature, oral tradition and/or your personal experience) that illustrate the issues that you discuss.

\section{Reflection on Exam Question 2 Submitted}

I submitted my response to written Exam Question 2 at 4:59pm on Friday, 1 minute shy of the 5 pm deadline. Submitting this concluded the written part of my comprehensive exam process.

In the next section the author describes the day before the oral defense and the oral exam process. As with many doctoral comprehensive exams there is a written and oral examination.

\section{Day 24}

Sick again as luck would have it. Monday came and I had not heard from my committee chair or anyone on my committee, no hints of what the oral defense would be, or if I would indeed be passing. Finally about 4 pm my committee chair calls me. He tells me some of my responses are interesting. Whenever anyone says something is interesting in academia it is not. As a student when someone says your responses are interesting, you realize that your responses are so far from a discipline, theory, or practice, that no other word quite describes what you have done. After decades as a student I have come to know this.

\section{The Oral Defense}

Tuesday, the day of my exam. I will not stress too much (But, it did not stop me from dusting off some epidemiology books from my time as a graduate student to review the quantitative methods section of my proposal). Never write something you cannot fully justify, articulate, or comprehend; with 2 epidemiologists on my committee, I should have reviewed this book sooner.

\section{Oral Exam Part I 3pm McIver Room 201}

I buy chocolate chip cookies thinking this will help. The meeting starts at 3pm. My committee members don't know each other well so the beginning dialogue is a bit uncomfortable. I sit down with my old green binder and I read some of the 107 pages I wrote and notice more errors and typos. I am feeling like this will never end. In the big conference room I am on one side of the 25 feet long table, and my committee chair and 3 members are opposite of me. My committee chair asks me about exam question 1; he wants to know what I would change. I say a lot. I babble on for about 20 minutes and finally say I need specifics or I will just go on for about 8 hours because there was a lot I would change- the typos, the style, theories, quantitative piece, tying everything together-how embarrassing this is as a doctoral student and professional. They excuse me from the room.

\section{Oral Exam Part II 415pm McIver Room 201}

My committee chair opens the door and I go back in and face more questions- they are endless, maybe even a little grueling. I do not recall all of them, but they included the following: Why did you place the quantitative analysis in Phase II of the study? Why didn't you give a description of the community first? Why did you use a phenomenological methodology instead of an ethnographic approach? Tell me how risk conditions are different than risk factors? What are the implications? Why did you select the age group?

There were specific questions in the oral exam process too, for example:

Committee Member 1- 'Why do you think this group of women experiences more risk factors than any other?' 
Student- 'Historical trauma, poverty, suicide, domestic violence, lack of education.'

Committee Member 3- 'Who are you comparing these women to?'

Student- 'Any population...' [Then I recall my written response compares them to non-Hispanic whites].

[Uncomfortable Silence...]

Committee Member 2- 'What would you say to the surgeon general about these findings?'

Student- 'I would not say anything. I would give the findings from this study to the community leaders and policy makers and let them decide what to say.'

[This was the wrong response, it came off as foolish and almost disrespectful to my most dedicated committee member, others laugh in the room and I immediately wish I could retract what I just said].

\section{You Passed \\ More discussion ensues and then I am asked to leave the room again. An hour and 15 minutes have passed but it feels like 8 hours at least. I walk back down the hallway, the one I use to walk every day as a graduate student. I find my old office mates and we laugh and talk. It is good to see them. Again, no review or planning for the next set of questions. My committee chair finds me in the room and calls me back. We discuss more of my answers. The exams have finally ended. I have passed. Paper work is signed and everyone congratulates me, for what I am not sure as I feel like the biggest fake or imposter there is.}

Future doctoral students, committee members, the academy, and family/other support networks should keep these four recommendations in mind: 1) planning for the process, 2) use a basic research design method and justification if applicable, 3) write letters, and 4) acknowledge selfdoubt (imposter syndrome) and move on.

Plan where, how, and when you write and think best. No matter how much one clears their calendars for comprehensive exams, there will always be menial tasks like writing birthday cards, watching 5-hours of Gold Rush with sick children, wiping down furniture that has not seen a dust rag in months, cleaning floors, picking weeds, even going through bins with old magazines to discard the old ones. Avoiding the inevitable of writing, reading, and rewriting caused me more anxiety and less time to put together a complete and well- thought-out response. Therefore, it is important for students to identify what they need to be successful and the environments that are most conducive to success. Also a strong support system is needed, especially for parents of children who may become sick.

Caution about innovation and context. Students must recognize that most researchers write about the same things in somewhat different ways. Few studies are truly innovative and often there is a reason for this- it is called generalizability, applicability, fundability, rigor, and evidence. When doctoral students try to be innovative they might actually lose ground or confidence of their committee. The exam process may be smoother if students select standard study designs with an acceptable evidence base. A student's training and professional experiences impact the ways they respond to exam questions, and students are taught that context matters. For example, the author's knowledge of research ethics, community context/capacity, and cultural norms were factors in how she approached the study design, research questions, methodology, and ethical questions. However, students must balance contextual factors with a solid research design, methodology, and justification.

Write letters. Students should write letters to committee members during and after the exams. If students wait to write letters, their emotions and vulnerabilities may be difficult to capture. This process also helps to bracket or set aside emotions. Letters also help committee members know 
how students approached the exam questions and provide insight into the challenges students have during the process. For example, one committee member said they realized the difficulty of the questions only after the author wrote the letter about the process. Letters also help committee members gain a deeper understanding of what it is like to be a doctoral student enduring the comprehensive exam process. Below is an excerpt from a letter that the author wrote and submitted with comprehensive Exam Question 1.

May 16, 2013

Dear Committee Member,

Before you begin reading my response, please know that I have thought these questions through to the extent I never wish to do so again. At times in the process I felt so completely inadequate that I wondered what I was doing and how I have come to this place. I wanted to spend this time, writing a proposal that might eventually do some good. In the last few years I have spent much time writing, of things that will never be used or seen again.

The entire experience has been humbling and maybe this is what I was supposed to learn through this process. Maybe, it was that I was not humble enough to do this kind of work in communities before now...

Imposter Syndrome. This syndrome is common in academe, and successful people with this syndrome often feel that they are a fraud and not worthy of success (see Cozzaraelli \& Major, 1990). Many students become aware of this syndrome at some point in their doctoral careers and during the exam process this feeling may increase. The author's experience with imposter syndrome is likely influenced by years of working in academia without a doctoral degree. Throughout this process there was a nagging feeling like I was not smart enough to earn a doctoral degree because other people always knew more than me. Below is an excerpt from the letter that accompanied Exam Question 2.

May 23, 2013

Dear Committee Member,

Before you read my responses to comprehensive exam question number2, please know that I have learned, in a short time, what not to do. The first set of questions I spent a great deal of time in the literature and by the time I was ready to respond to the first set of questions and design a study-it was too late. Dr. Jones told me weeks ago that I should not spend a lot of time in the literature, but I did this anyway. The best way to learn is to try something the wrong way and fail. Experience is the best teacher and therefore this week, I tried to use my own experiences relating to the exam questions. However, the week passed quickly (week 1 of comps was difficult because my daughter was home sick all week with asthma issues, then week 2 I found what I wanted to write about, but kept reading, week 3 I had a strategy set-but of course things never go as planned). These are not excuses but simply my reality. So, the drafts you receive are imperfect and I look forward to seeing you all soon to defend them.

\section{Conclusion}

This paper illustrates the use of autoethnographic approaches in research with the aim of 'making sense' of an experience while gaining a deeper understanding of self in relation to others. Unlike other qualitative research methods that require extensive data collection, analysis, or coding to 'get it right' or find the truth - autoethnography speaks truth from the beginning. The author discloses without hesitation her experience and for many this untypical truth telling in research un- 
covers the meaning of human experience. Autoethnography as a research method helped the author make sense of the comprehensive exam process and deepened her understanding of who she was and who she was not. I know that if I had the chance to take my comprehensive exams over again, I would. I would know more about what to expect, how to prepare, and the kinds of support I needed to be successful. Writing and reflection (reflexive autoethnographic approach) helped me understand the full meaning of the experience.

In Closing. Doctoral students benefit when the comprehensive exam process allows for reflexivity. Although, most comprehensive exams rely on more traditional research methods, doctoral students and committee members must be open and supportive in the multiple ways that students express their emotions, design exam responses, and deal with the realities of life during the exam process. Most students are like the author, they do not have the luxury of checking into a quiet hotel room for weeks on end to write responses to exam questions. In fact, many students in similar situations lack social support and often report feelings of social isolation (Ali \& Kohun, 2007). For me, the exam process was not about passing exams and being one step closer to a doctoral degree; the process was about becoming human again after the years of graduate studies, final exams, and sleepless nights worrying about classes, homework, publications, and life balance. I encourage students to reflect on their histories and experiences and find ways to relate these to the challenges they face in the comprehensive exam process. We do not need statistical tests to validate our existence. Our lives and experiences are significant; they help us live in a meaningful way. Students and scholars alike must strive to exist in ways that are humble, non-judgmental, accepting, vulnerable, and open to a world in which realities, many truths, and experiences can be found.

May 23, 2013

Dear Committee Member.

I am thankful to God for the people that he has put in my life at a time they were most needed to teach me the things that I need to know to continue in a good way. You are these people at this time.

\section{References}

Aguirre, A., Jr. (2000). Women and minority faculty in the academic workplace: Recruitment, retention, and academic culture. ASHE-ERIC Higher Education Report, 27(6). Jossey-Bass Higher and Adult Education Series. San Francisco, CA: Jossey-Bass.

Ali, A., \& Kohun, F. (2007). Dealing with social isolation to minimize doctoral attrition- A four stage framework. International Journal of Doctoral Studies, 2(1), 33-49. Retrieved from http://www.ijds.org/Volume2/IJDSv2p033-049Ali28.pdf

Becker, H. S. (1967). Whose side are we on? Social Problems, 14, 239-248

Berry, K. (2006). Implicated audience member seeks understanding: Reexamining the" gift" of autoethnography. International Journal of Qualitative Methods, 5(3).

Carter, S. M., \& Little, M. (2007). Justifying knowledge, justifying method, taking action: Epistemologies, methodologies, and methods in qualitative research. Qualitative Health Research, 17(10), 1316-1328. doi: $10.1177 / 1049732307306927$

Chang, H. (2008). Autoethnography as method. Walnut Creek, CA: Left Coast Press.

Creswell, J. (2007). Qualitative inquiry \& research design: Choosing among the five approaches. Thousand Oaks, CA: Sage.

Cozzarelli, C., \& Major, B. (1990). Exploring the validity of the impostor phenomenon. Journal of Social and Clinical Psychology, 9(4), 401-417. 
Daniel, M., Green, L. W., Marion, S. A., Gamble, D., Herbert, C. P., Hertzman, C., \& Sheps, S. B. (1999). Effectiveness of community-directed diabetes prevention and control in a rural Aboriginal population in British Columbia, Canada. Social Science \& Medicine, 48(6), 815-832.

Delamont, S. (2007, September). Arguments against auto-ethnography. In paper presented at the British Educational Research Association Annual Conference (Vol. 5, p. 8).

Denzin, N., \& Lincoln, Y. (Eds.). (1994). Qualitative Research. Thousand Oaks, CA: Sage

Ellis, C. (1999). Heartful autoethnography. Qualitative Health Research, 9(5), 669-683.

Ellis, C. (2004). The ethnographic I: A methodological novel about autoethnography (Vol. 13). Rowman Altamira.

Ellis, C., Adams, T. E., \& Bochner, A. P. (2011). Autoethnography: An overview. Historical Social Research/Historische Sozialforschung, 273-290.

Ellis, C., Bochner, A., Denzin, N., Lincoln, Y., Morse, J., Pelias, R., \& Richardson, L. (2008). Talking and thinking about qualitative research. Qualitative Inquiry, 14(2), 254-284.

Guba, E. G., \& Lincoln, Y. S. (1994). Competing paradigms in qualitative research. Handbook of Qualitative Research, 2, 163-194.

Jones, M., \& Alony, I. (2011). Guiding the use of grounded theory in doctoral studies--An example from the Australian film industry. International Journal of Doctoral Studies, 6, 95-114. Retrieved from http://ijds.org/Volume6/IJDSv6p095-114Jones322.pdf

Kaufman, G., \& Uhlenberg, P. (2000). The influence of parenthood on the work effort of married men and women. Social Forces, 78(3), 931-947.

Kempster, S., \& Stewart, J. (2010). Becoming a leader: A co-produced autoethnographic exploration of situated learning of leadership practice. Management Learning, 41(2), 205-219.

Krefting, L. A. (2003). Intertwined discourses of merit and gender: Evidence from academic employment in the USA. Gender, Work \& Organization, 10(2), 260-278.

Langhout, R. D. (2006). Where am I? Locating myself and its implications for collaborative research. American Journal of Community Psychology, 37(3-4), 267-274.

Mcllveen, P. (2008). Autoethnography as a method for reflexive research and practice in vocational psychology. Australian Journal of Career Development, 17(2), 13-20.

Meekums, B. (2008). Embodied narratives in becoming a counselling trainer: An autoethnographic study. British Journal of Guidance \& Counselling, 36(3), 287-301.

Polkinghorne, D. E. (1991). Narrative and self-concept. Journal of Narrative and Life History, 1(2-3), 135153.

Riessman, C. K. (2008). Narrative methods for the human sciences. Sage.

Smallwood, S. (2004). Doctor dropout. The Chronicle of Higher Education, 50(19), A10.

Smith, D. E. (1987). The everyday world as problematic: A feminist sociology. University of Toronto Press.

Spry, T. (2001). Performing autoethnography: An embodied methodological praxis. Qualitative Inquiry, $7(6), 706-732$.

Starr, L. J. (2010). The use of autoethnography in educational research: Locating who we are in what we do. CJNSE/RCJCE, 3(1).

Vande Berg, L., \& Trujillo, N. (2008). Cancer and death: A love story in two voices. New York: Hampton.

Wall, S. (2008). An autoethnography on learning about autoethnography. International Journal of Qualitative Methods, 5(2), 146-160.

Winslow, S. (2010). Gender inequality and time allocations among academic faculty. Gender \& Society, 24(6), 769-793. 


\section{Biography}

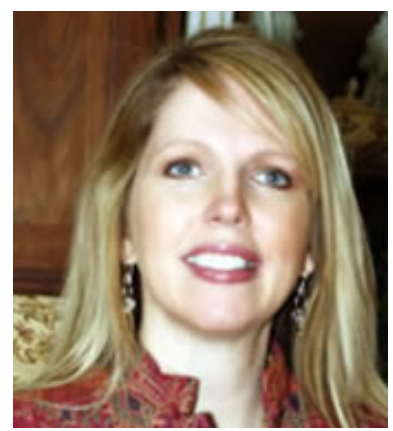

Allyson Kelley is a community health evaluation research scientist with interests in building community capacity to address the cultural, social, and environmental factors that contribute differences in health outcomes in American Indian communities. She holds an adjunct assistant professor appointment in the Department of Public Health Education at the University of North Carolina at Greensboro. She earned her Master's degree in Public Health Practice from the University of Alaska Anchorage and her Doctorate in Public Health Education from the University of North Carolina at Greensboro. Her interests are driven by what communities identify as most important. Most of her work is in Tribal communities where she works with Tribal organizations such as health departments, boys and girls clubs, Tribal Leaders, recovery programs, Tribal colleges, environmental departments, and non-profits. Allyson has worked with Tribal communities since 2005-as a research partner, evaluator, methodologist, educator, and research ethics advisor. Her efforts have resulted in funding and implementation of several successful programs aimed at building capacity to address disparities using strength- based approaches. She currently resides in New Mexico and is an independent consultant for a variety of Tribal public health initiatives. 